\title{
Monitoring and Controlling Electric Power Stations Using GSM Network
}

\author{
Goran H. Ismail \\ Electrical Engineering Department \\ Faculty of Engineering \\ University of Sulaimani \\ Sulaimani, Iraq \\ goran.hama@gmail.com \\ Asso R. Majeed \\ Electrical Engineering Department \\ Faculty of Engineering \\ University of Sulaimani \\ Sulaimani, Iraq \\ asso.majeed@univsul.edu.iq
}

\author{
Bilal A. Mubdir \\ Communication Department, \\ Technical Institute of Sulaimani \\ Sulaumani Polytechnic University \\ Sulaimani, Iraq \\ bilal.mubdir@spu.edu.iq \\ Asaad M. Jassim Al-Hindawi \\ Communication Engineering Department \\ Technical College of Engineering \\ Sulaimani Polytechnic University \\ Sulaimani, Iraq \\ asaad.jasim@spu.edu.iq
}

Volume 4 - Issue 2

December 2019

DOI:

10.24017/science.2019.2.7

Received:

23 July 2019

Accepted:

03 October 2019

\begin{abstract}
This paper introduces a system design for monitoring and controls the components of power generation station and substation with help of existing communication link based on GSM network. In this design, a selected Programmable Logic Controller (PLC) connected to the fields that needed to be monitored and continuously read changes in measurements of electrical parameters like voltage, current, bus bar circuit breakers.....etc. . These parameters have been monitored by PLC, on the base of conditions that PLC is programmed. PLC generates a text message and forward to other side; control center or mobile phone of engineer and technicians; who are responsible of monitoring. At control center, another GSM modem which has capability to connect with personal computer, receives that text massage using SMS and executes it. Software written with Vb.Net, works as Human Machine Interface (HMI) for this purpose. The system performance is acceptable in terms of errors in readings and time delay. The percentage error for the current is about $1 \%$, and for the voltage is about $0.2 \%$. The delivery time to receive new analog and digital inputs data is about 14.125 seconds, while the control of the circuit done after 4.68 seconds.
\end{abstract}

Keywords: GSM Modem, HMI, PLC, Sensor, SMS 


\section{INTRODUCTION}

At present, the recent technologies developed strongly and the popularity for the electric vehicles is increasing and so the energy consumption is increasing day by day. The Energy represents the vital need of the humans being where the energy demand is much greater than the actual energy generated in almost all countries. The Energy considered as one of the basic infrastructure for the growth of any economy and a key factor in assessing the progress of any country. In the last two decades, many studies have been conducted to design and implement different types of electrical power management systems based on the use of modern telecommunication system, such as those conducted by Ganiyu, et al [1], and Al-Hindawi, et al. [2],[3],[4] for the system management and electric energy saving. In those papers, an inexpensive products have been used to establish monitoring and control system based on an open source software.

Dabont, et al. [5] found that the long distance between generators and loads was an important parameter. Thus, large quantity of energy exchanges through long distances has been transformed by the lack of electrical power; a great deal of energy is lost during the transmission of generated energy, resulting in a reduction in the amount of energy received at substations. Therefore, measurements must be obtained either by one party or by both parties. Petrescu, et al. [6] designed and implemented a system of monitoring and control based on SMSfor the application of telemetry. They tested some wireless technologies, but they focused on the GSM modem and the efficiency of using SMS. SMS is used to report a particular position such as power outages. In addition, a controller is used as a processing unit and a GSM modem used for communication purposes.

Jawarkar et al. [7] developed a remote control system and mobile-based controls, and alerts the user when abnormal conditions such as power outages occur. They have programmed an algorithm to create a text message that can be transmitted to the user's phone. Their system embodies a mobile device designed to connect to the GSM network and receive and execute the desired arrangement of the user.

Xiao, et al [8] presented a system depends on the GSM network, which can monitor the power lines reliably. Using the SMS service, the network is realized for remote data transfer. The system consists of a control center and smart power lines monitoring instruments. This system was mainly based on information theory and SMS system that are analyzed.-Instruments consist of hardware and software designs. The hardware design consists of the 89C2051 microcomputer, the data transmission mode of GSM, the ground line monitoring service, the IC memory card module (the identification card), and so on. Using the SMS G100A serial connection controller, the performance of data transmission could be efficient. The designs of communication protocol and transceiver program were the basic of the software programs. Test results and practicality show that the design of this system can meet user requirements. This system will be strongly applied in many fields and has a great economic level.

Sachan[9]introduced a project to obtain remotely the electrical parameters such as voltage, current and frequency and transmit these values in addition to the temperature at the power plant in real time via modem / phone based on GSM network system. By using arunning electromagnetic relay, the proposed system can protect the electric circuits. When the electrical parameters exceed certain values that are specified previously then the relay will be on. This relay can activate the circuit breaker in order to turn off the main power source. The reading of electric parameters could be obtained remotely when the user transmits the required commands in the shape of SMS. At regular periods the user can receive the electrical parameters in real time as short massages (depends on time setting).The designed system can alert the user via SMS when the circuit breakers are disconnected or when the voltage or current increases over the preset levels. The proposed project uses a computer on board, usually called a microcontroller. This computer can communicate efficiently with the required various sensors. For holding the required code, some of internal memory is provided with the 
used controller. The function of this memory is to dump some set of assembly instructions in the controller. The work of the controller depends on these assembly instructions. It is programmed based on the built-in C language. Jusoh, et al. [10] designed a smart Remote Terminal unit (RTU) which is used as an automatic technology for low voltage (LV) downstream operation of $415 / 240 \mathrm{~V}$ to increase the power reliability of consumers. The proposed design depends on (GSM) communication. Siregar, et al.[11] used the ACS712 sensor and the voltage sensor based on the circuit of voltage divider and communicating by GSM system for controlling the battery and the solar panel. The data obtaining from the current and voltage sensors are then processed by a microcontroller. Bhaskarwar, et al. [12] studied and focused on control system implementation of heat exchangers of the type of shell and tube through a number of tools such as PLC, Supervisory Control and Data Acquisition SCADA, Lab VIEW and the Internet.

The above efforts and works can serve and support the smart grid technology that basically consists of smart meters, sensors, proper monitoring and data management system $[13][14][15][16]$. The point of the present proposed system in this paper, related to the above selected papers, is most of the work done before, SMS has been used to monitor and control the home appliances, transformer and single cable. While in this paper, the proposed system is to use SMS service of GSM data transmission network as a simple and easy communication link between the power station and the power substations and control centers for the purpose of monitoring and control. In this kind of system there is high number of signals, therefore time delay is significant, and the control centers transceivers "GSM modem" topology must be designed carefully. Therefore, a remote monitoring and control system is designed and developed using SMS technology. SMS uses signaling channels instead of custom data channels. These messages can be transmitted / received at the same time via proposed GSM link. The main feature of using SMS is to follow the method of storage and forwarding, and SMS processing can go on during the specified validity period if the network is currently busy or if the user is outside the coverage area. The proposed system offers several features like:

1. Monitor remote electrical parameter like "voltage, current, frequency....etc."

2. Receive status of circuit breakers.

3. Send control command to change status of breakers remotely.

4. The defined user can send read command to monitor specific parameter.

SMS users or technicians working on this system can alert when abnormal conditions occurred such as power outages, over-rated parameters, or any other abnormal situation.

\section{PROPOSED SYSTEM DESIGN}

The proposed system design consists of electrical power generating plants, power substation and control center, as shown in figure1. The proposed communication link between them is based on SMS of GSM network and this needs programmable logic controller PLC (at the generating plant and substation) to gather information from the field and GSM modems as transceivers. 


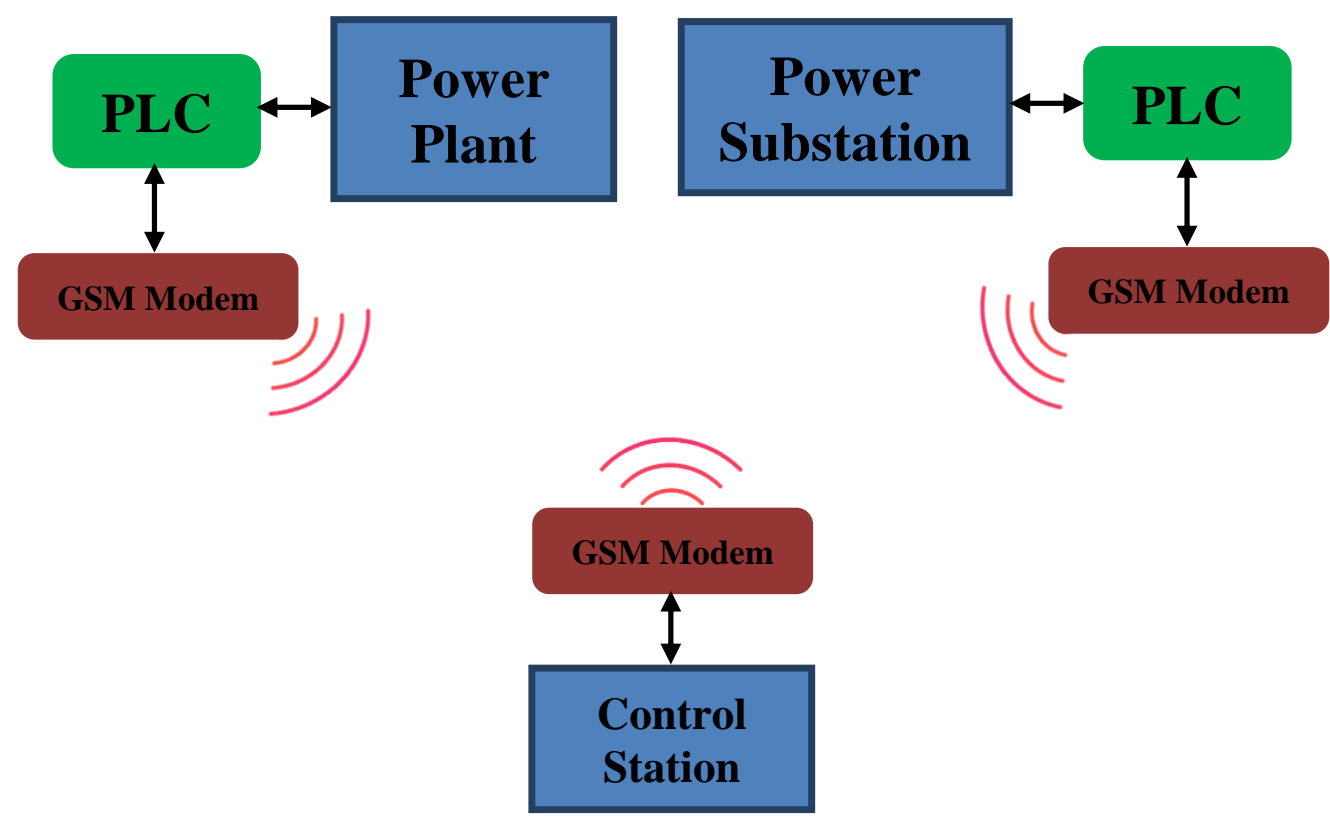

Figure1: Block diagram of proposed system based on GSM.

The electrical station (may represent the power generating plant or substation) consists of, transducers, relay, AC to DC convertor, PLC, and GSM modem while the control center consists of GSM modem, cell phone and HMI, as plotted in figure 2 and as follows:

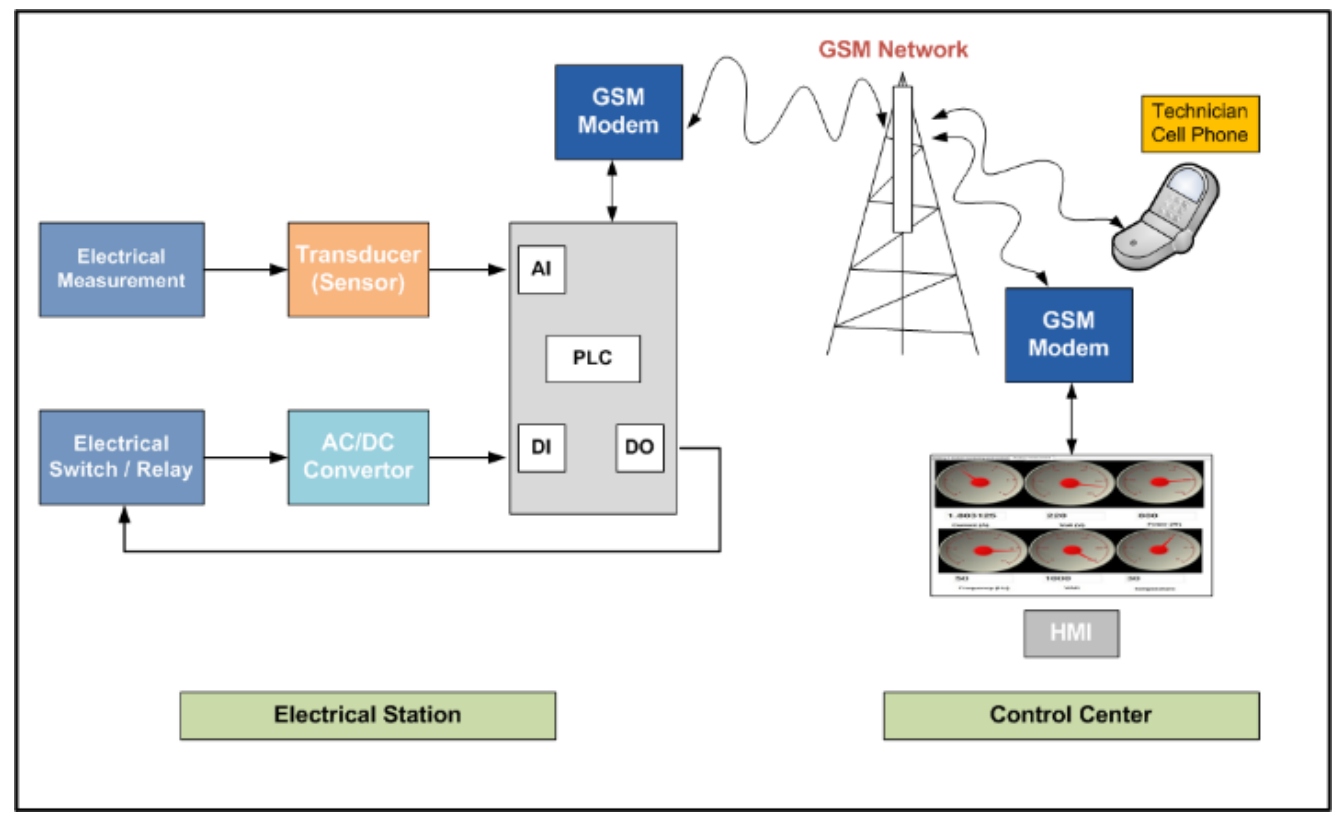

Figure 2: Block diagram of the electrical station and control center. 
1. Sensor: It is an energy transformer designed to sense (in the sense of discovering) some of the characteristics of its surroundings [17]. It is used to detect the parameter in one form of energy, and to report it in a certain amount of material. The input signal to the transducer will be changed to physical quantity at output; there are many types of sensors based on output signal such as bipolar signals $( \pm 2 \mathrm{~V}, \pm 10 \mathrm{~V})$, true Zero signals $(0-2 / 10 \mathrm{~V} \mid 0-20 \mathrm{~mA})$ and live Zero signals $(1 / 2-10 \mathrm{~V} \mid 4-20 \mathrm{~mA})$.

2. Relay: A relay is usually an electromechanical device that used to close the open circuit or to open the closed circuit when the current or voltage on the coil of relay is changed. Digital output in programmable logic controller (PLC) is working as switch to close and open power on the coil terminals.

3. AC/DC Convertor: The circuit switch status connected to digital input of PLC must be a DC voltage, the value of highest DC voltage that PLC consider as ON depends on the PLC configuration. The PLC used in our system input voltage with (24) VDC represents ON and (0) VDC is OFF status. A 220 VAC to 24 VDC convertor is used, the output terminals of DC voltage connected to input of PLC.

4. Programmable Logic Controller (PLC): The word "programmable" is distinguished from the conventional hard-wired relay logic. It can be easily programmed or changed according to the required application. The PLC passed the risk of changing the wires. The most important PLC ingredientsare [18]:

Power Supply:It can be an external unit or can be built in same PLC. The common required voltage levels at the PLC (with and without power supply) are 24Vdc, 120Vac, 220Vac.

Central Processing Unit (CPU):It is a computer where the logic of the ladder is stored and processed.

Input/output (I/O):A number of input / output terminals are provided so that PLC can monitor the process and initiate actions. There are two analog and digital PLC I / O.

Analog measurement:Analog data includes all continuous and variable signals over time from the domain. Examples include current, voltage, active energy, interactive power, power factor, etc.

Digital measurement:Digital signals are intermittent signals that change from one state to another in descriptive steps, and separate signals behave as binary keys, simply leading to a signal (on or off) ( 1 or 0 , True or False, respectively). Digital signals include switching positions, isolation positions and circuit breakers in the power system.

5. GSM Modem: A GSM modem is a specialized type of modem that accepts a SIM card and operates via a subscription to a mobile phone operator, just like a mobile phone, it can be a dedicated modem device with a serial connection. Instructions AT commands used to control the modem. AT is the abbreviation Attention, and each command line starts with "AT" and for this reason modems are sometimes called AT commands. The GSM modem supports a set of GSM AT commands that include relevant SMS commands such as AT + CMGS, AT + CMSS, AT + CMGL (SMS list), AT + CMGR (Read SMS message).

6. Human Machine Interface (HMI): For monitoring and control purpose, the operators can use the mobile phone or can use a software as human machine interface (HMI). HMI presents the measured values, generate alarms, and sent control commands...etc. The visual studio is used to create HMI. The used GSM modem is Wavecom WM 17253, the port settings are: Baud Rate 9600, Data Bit 8, Stop bit 1 and Flow control none. The software connection illustrated with flow chart in figure 3 . 


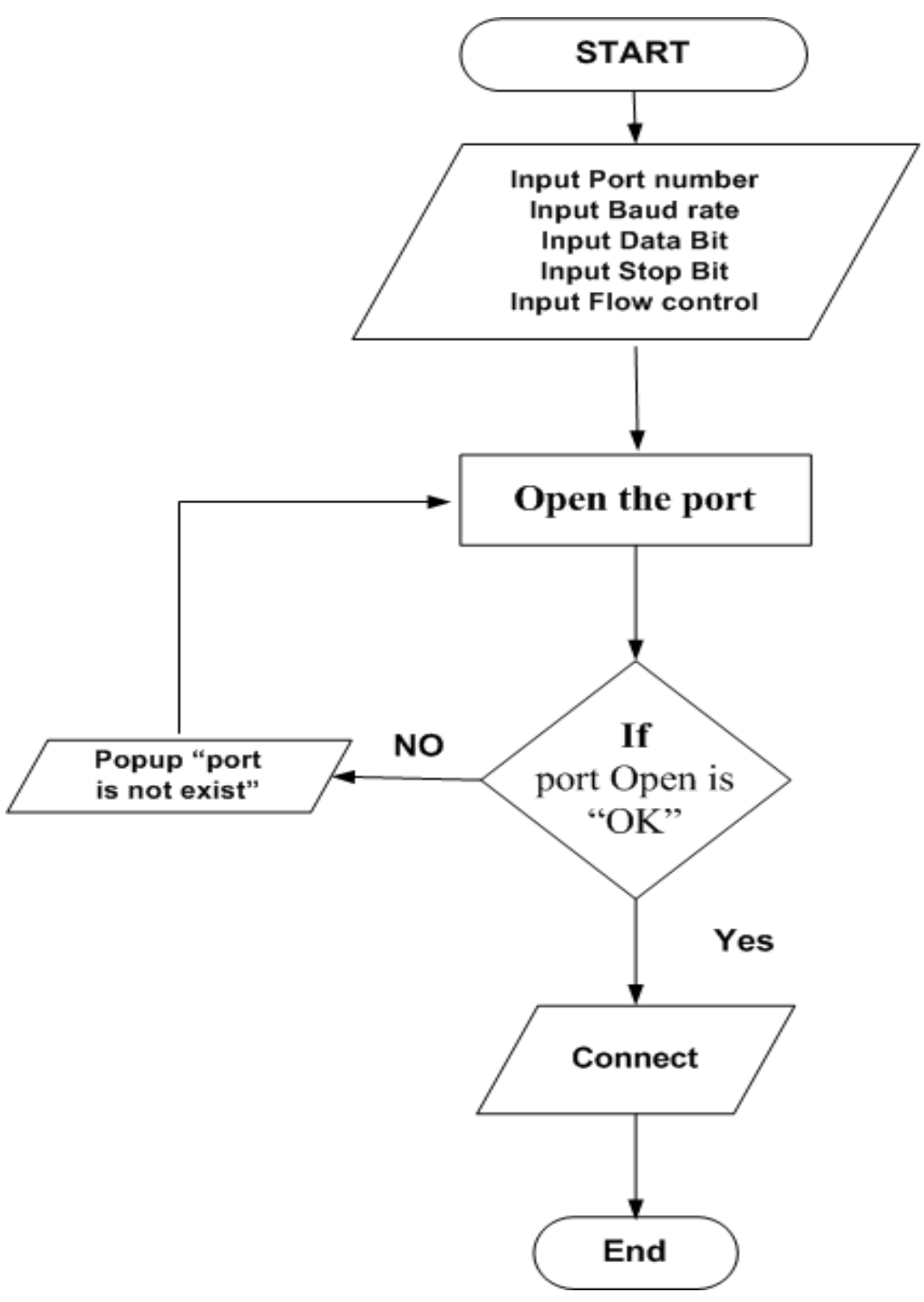

Figure3: Flow chart of serial port connection [3].

\section{RESULTS OF THE SYSTEM TEST AND DISCUSSION}

A modeled system designed and tested in the lab, an electrical circuit with variable AC source and resistor used to generate the desired current. The measurements are monitored by using two transducer, 24 VDC relay used to control electrical circuit remotely, as it can be seen the single line diagram in figure 4 . The current desired in the circuit connected to a current transducer " $0-5 \mathrm{~A}$ " and AC source connected to a voltage transducer " $0-250 \mathrm{VAC}$ ", the output of the transducers are 4-20 mA. The output of transducers connected to analog inputs of PLC. An AC to DC transformer is used to convert the AC input voltage of the circuit to 24 VDC, the VDC output is a circuit switch status, 0 VDC means circuit switch OFF, 24 VDC means circuit switch ON. The PLC is programmed for any new reading of current or voltage and circuit status (ON/OFF) sent the data by SMS to mobile phone or another GSM modem that connected to PC and decode new message by HMI that is written by using Vb.Net, also the user can send a control command to Switch ON/OFF remotely by sending SMS the content of message must be the same as it defined at the PLC. 
The system tested in different ways to see the performance of the communication link based on SMS of GSM technology.

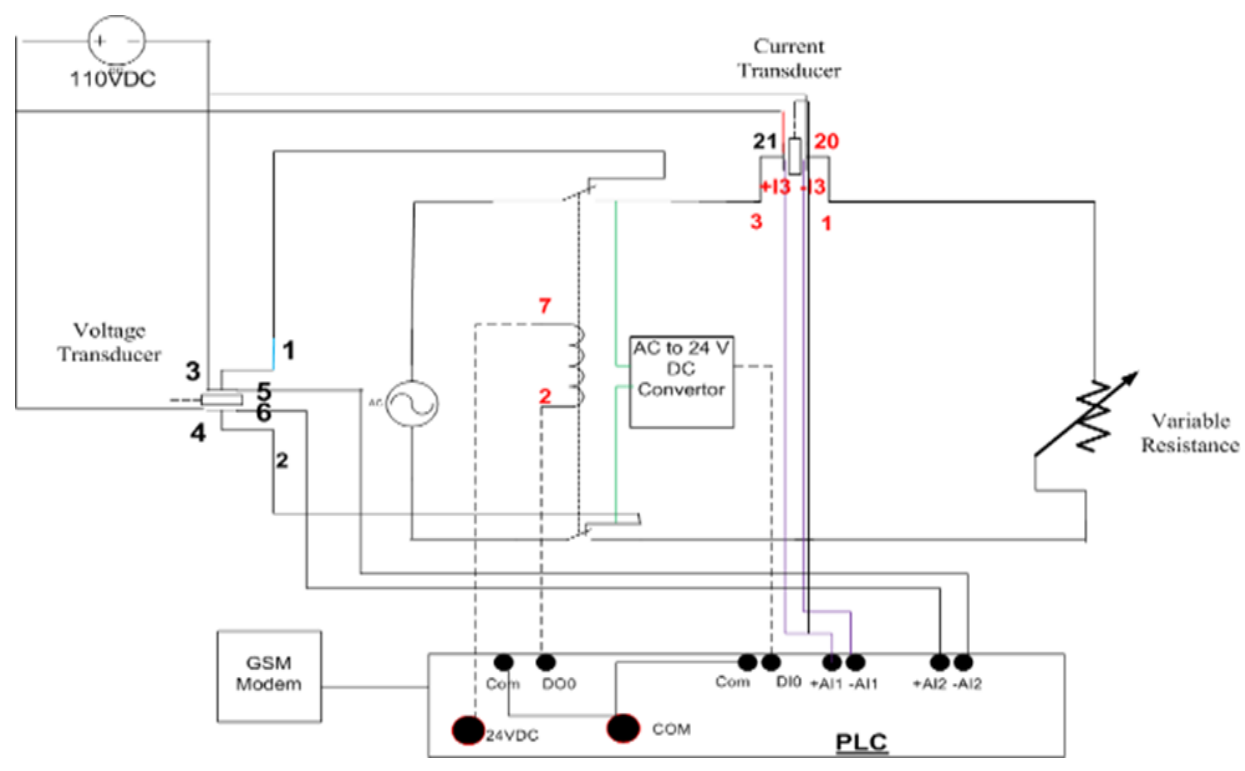

Figure 4: Virtual lab prototype single line diagram

3.1. Monitor Circuit with Cell Phone: The data of sent current, voltage measurement and switch status to mobile phone, are merged in one SMS. The test performed by changing variable resistance or variable voltage, the delivery time for new status by mobile phone measured as illustrated in Table 1 .

Table 1:SMS delivery time to mobile phone

\begin{tabular}{ccccc}
\hline \multicolumn{2}{c}{ Multi-meter } & \multicolumn{2}{c}{ SMS receive } & \multirow{2}{*}{$\begin{array}{c}\text { Deliver Time } \\
\text { (second) }\end{array}$} \\
\cline { 1 - 4 } Current & Voltage & Current & Voltage & 10.65 \\
\hline $\mathbf{0 . 6 4}$ & 220.5 & 0.63 & 220.31 & 12.55 \\
\hline $\mathbf{1 . 9 5}$ & 224.8 & 1.93 & 224.80 & 11.30 \\
\hline $\mathbf{2 . . 6 1}$ & 205 & 2.60 & 205.10 & 14.81 \\
\hline $\mathbf{3 . 2 3}$ & 221 & 3.21 & 221.00 & 12.25 \\
\hline $\mathbf{0 . 6 6}$ & 220.2 & 0.65 & 220.00 & 10.92 \\
\hline $\mathbf{1 . 9 9}$ & 230 & 1.96 & 229.40 & 13.92 \\
\hline $\mathbf{1 . 2 2}$ & 220 & 1.21 & 220.31 & 12.22 \\
\hline \multicolumn{5}{c}{ Average } \\
\hline
\end{tabular}

It can be shown from Table 1, the average time to deliver a status of new reading with a mobile phone is nearly 12.22 seconds. If it compared to the normal SMS delivery between two mobiles, the average time is 4.94 second. Where, the difference is 7.28 seconds. This difference is the time that the transducer converts new input to 4-20 mA, PLC scanning input that is normally around ( $0-5$ seconds) and transmits this new status to the serial port.A sample of received SMS to a mobile phone can be described in Figure 5 which shows the receive a message with 16-signals which are separated by comma (,). The first eight signals are analog inputs and the last eight signals are digital inputs measurements connected to the PLC, the second reading is current measurement $(0.63 \mathrm{~A})$, the third reading is voltage measurement (230.31) and the signal number nine is the circuit status (1) is means the circuit is switched on. 


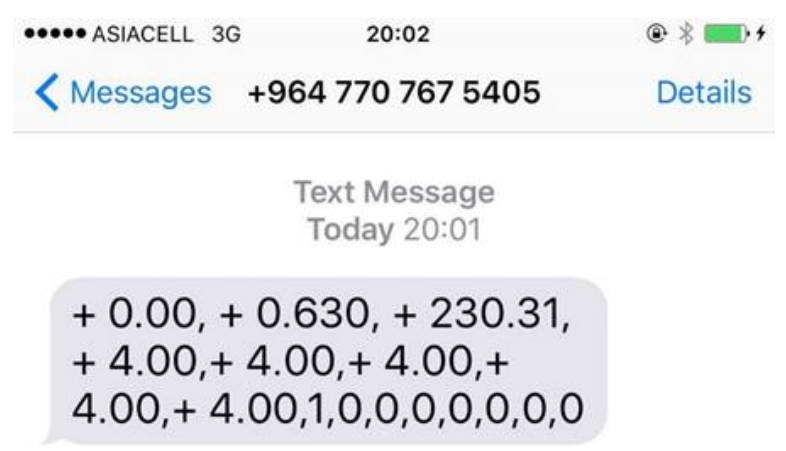

Figure 5: Mobile phone receive SMS.

3.2. HMI for Circuit Monitoring and Control: The HMI used for this test created by using visual basic; the same connection in section 3.1 is used. The results are shown in Table 2 .

Table 2: SMS delivery time with HMI

\begin{tabular}{ccccccc}
\hline $\begin{array}{c}\text { HMI } \\
\text { Current }\end{array}$ & $\begin{array}{c}\text { Multi- } \\
\text { meter } \\
\text { Current }\end{array}$ & $\begin{array}{c}\text { Error } \\
\text { percentage }\end{array}$ & $\begin{array}{c}\text { HMI } \\
\text { (Voltage) }\end{array}$ & $\begin{array}{c}\text { Multi- } \\
\text { meter } \\
\text { voltage }\end{array}$ & $\begin{array}{c}\text { Error } \\
\text { percentag } \\
\text { e }\end{array}$ & $\begin{array}{c}\text { Time } \\
\text { (sec.) }\end{array}$ \\
\hline $\mathbf{0 . 6 5 6 2 5}$ & 0.66 & $0.5682 \%$ & 223.4375 & 225.7 & $1.0024 \%$ & 12.08 \\
\hline $\mathbf{1 . 3 2 1 8 7 5}$ & 1.34 & $1.3526 \%$ & 224.6875 & 224.5 & $0.0835 \%$ & 15.86 \\
\hline $\mathbf{1 . 9 6 8 7 5}$ & 1.99 & $1.0678 \%$ & 223.28125 & 223.2 & $0.0364 \%$ & 14.05 \\
\hline $\mathbf{2 . 6 2 8 1 2 5}$ & 2.68 & $1.9356 \%$ & 222.1875 & 222.2 & $0.005 \%$ & $15 . .25$ \\
\hline $\mathbf{3 . 2 9 6}$ & 3.32 & $0.7229 \%$ & 220.78125 & 221 & $0.099 \%$ & 14.24 \\
\hline $\mathbf{1 . 8 0 9 3 7 5}$ & 1.84 & $1.6644 \%$ & 205.78125 & 205.7 & $0.0395 \%$ & 14.76 \\
\hline $\mathbf{1 . 2 1 2 5}$ & 1.22 & $0.6148 \%$ & 205.9375 & 205.7 & $0.1155 \%$ & 12.08 \\
\hline $\mathbf{1 . 8 0 3 1 2 5}$ & 1.84 & $2.0041 \%$ & 205.46875 & 205.4 & $0.0335 \%$ & 14.68 \\
\hline Average & $1.2413 \%$ & & & $0.1769 \%$ & 14.125 \\
\hline
\end{tabular}

As it can be observed in Table 2, the average time to receive a new measurement and represent it on HMI is 14.125 seconds. The time difference for monitoring the same circuit by mobile phones in previous test is 2.186 seconds. This extra time delay is because of execution time needed by visual basic and presents it on monitoring window. The precision of the result in HMI compared to the measurements in multi-meters for the current is about of $2 \%$ and for the voltage is about of 1\%. Example for last results in Table 2 is shown in figure 6.

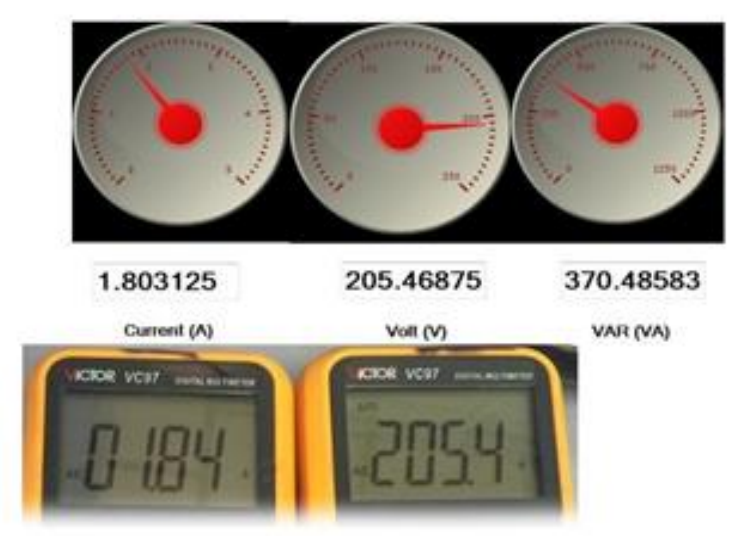

Figure 6: Result comparison HMI with multi-meter 
3.4. Sending Control Commands: The time needed for controlling electrical circuit breakers is very significant, for the proposed system, the times is measured when a message is sent to change switch status and the updated data presented on HMI, the results are shown in Table 3.

Table 3: Control circuit time

\begin{tabular}{ccc}
\hline $\begin{array}{c}\text { Current / New } \\
\text { Status }\end{array}$ & $\begin{array}{c}\text { Circuit Switch Change } \\
\text { Time (sec.) }\end{array}$ & $\begin{array}{c}\text { HMI update } \\
\text { Time (sec.) }\end{array}$ \\
\hline OFF/ON & 6.75 & 24.02 \\
\hline ON/OFF & 4.26 & 20.20 \\
\hline OFF/ON & 4.63 & 22.46 \\
\hline ON/OFF & 2.94 & 19.21 \\
\hline OFF/ON & 3.84 & 20.11 \\
\hline ON/OFF & 5.23 & 21.67 \\
\hline OFF/ON & 6.36 & 22.31 \\
\hline OFF/ON & 3.46 & 19.73 \\
\hline Average & 4.68 & 21.21
\end{tabular}

From Table 3, the time needs to change switch status by using SMS is about $(4.68 \mathrm{sec}$.$) and$ (21.21 sec.) to update HMI for new switch status.

\section{CONCLUSIONS}

The proposed system has two main parts which are prototyped and tested successfully by using an existing GSM infrastructure. First part was the unit that designed to be installed in the power station and aggregate the sensors readings and processed them into a packet ready to send for the monitoring side. Second part was the HMI, that designed by using GSM modem and an application built based on Visual Basic open source platform in order to visualize the received packets of reading from the power stations. PLC was used in the first part due to its simplicity and reliability for the industrial and heavy duties usage. The proposed system with its features is very fixable and ready for any expansion without any revisions on the current installed units. Testing the system in different situations and environments show that the operation is very easy and cost effective since the only paid cost is the SMS toll by the sending side. The time required for the message to be delivered is ranged from 19 to 24 seconds, where 21.21 seconds was the average delay time for the message to be delivered. This time is adequate for monitoring and control purposed in a soft real time application. For applications that required hard real time, it is recommended to use a technique that provides less delay.

\section{REFERENCE}

[1] R. Ganiyu, O. Arulogun,A. Adetunji, O. Okediran, "Development of a GSM Based Household Power Management System”, British Journal of Science, Vol. 1 (2), 1 September 2011.

[2] B. Mubdir, A. Al-Hindawi, N. Hadi, "Design of Smart Home Energy Management System for Saving Energy", European Scientific Journal, Edition, Vol. 12, No. 33, pp. 521-536, 2016.

[3] N. Hadi, B.Mubdir, A. Al-Hindawi, A. Ahmed, "Design and Implementation of Smart Home Energy Management System Based on GSM Network”, Kurdistan Journal for Applied Research, Volume 2, Issue 3, 2017.

[4] B. Mubdir, A. Al-Hindawi, S.Hussien, H. Al-Rizzo, "Smart Energy Monitoring and Control System Based on Wireless Communication", International Journal of Engineering and Advanced Technology, Vol. 3 Issue 1, pp. $1-6,2013$

[5] P. Daponte, M. Di Penta, G.Mercurio, “TransientMeter: A Distributed Measurement System for Power Quality Monitoring”, IEEE Transactions on Power Delivery, Vol. 19, Issue. 2, pp. 456-463, 2004. 
[6] B. Petrescu, D. Chiciudean, R. Cioarga, D. Stanescu, "Wireless Solutions for Telemetry in Civil Equipment and Infrastructure Monitoring”, 3rd Romanian-Hungarian Joint Symposium on Applied Computational Intelligence (SACI), May 25-26, 2006.

[7] N. Jawarkar, V. Ahmed, S. Ladhake, R. Thakare, "Microcontroller Based Remote Monitoring using Mobile through Spoken Commands", Journal of Networks, Vol. 3, No. 2, 2008.

[8] J. Xiao, Shou Xu ; Guohe Wu "Monitor system of the intelligent power earth lines based on GSM SMS protocol”, 9th International Conference on Electronic Measurement \& Instruments.( ICEMI '09), Beijing, 16-19 Aug. 2009.

[9] A.Sachan "Microcontroller Based Substation Monitoring and Control System with Gsm Modem",IOSR Journal of Electrical and Electronics Engineering (IOSRJEEE), ISSN: 2278-1676 Volume 1, Issue 6, pp.13-21, JulyAug. 2012.

[10] W.Jusoh, M. Ghani, W.Hanafiah, M.A.; S. Raman, "Development of a new modeling circuit for the Remote Terminal Unit (RTU) with GSM communication”, 2013 IEEE Conference onClean Energy and Technology(CEAT), pp.18-20, 2013.

[11] S.Siregar, D. Soegiarto, "Solar Panel and Battery Street Light Monitoring System Using GSM Wireless Communication System",Second International Conference on Information and Communication Technology (ICOICT), 2014.

[12] T.Bhaskarwar, S. Giri, R. Jamakar, "Automation of shell and tube type heat exchanger with PLC and LabVIEW”, Industrial Instrumentation and Control (ICIC) International Conference, 2015.

[13] M. Rehmani, A. Davy, B. Jennings, C.Assi, "Software Defined Networks-Based Smart Grid Communication: A Comprehensive Survey", IEEE Communications Surveys \& Tutorials, vol. 21, no. 3, pp. 2637-2670, 2019.

[14] A. Abbasi, A. Abbasi, S. Shamshirband, A.Chronopoulos, V. Persico, A. Pescapè, "Software-Defined Cloud Computing: A Systematic Review on Latest Trends and Developments", IEEE Access, Vol. 7, pp. 93294-93314, 2019.

[15] S. Reka, T. Dragicevic, P. Siano, S. Prabaharan, "Future Geharation 5G Wireless Network for Smart Grid: A Comprehensive Review", Energies Journal, Vol. 12, Issue 11, 2019. https://doi.org/10.3390/en12112140

[16] O. Machidon, C. Stanca, P. Ogrutan ,C. Gerigan, L. Aciu, "Power-system protection device with IoT-based support for integration in smart environments",PLOS ONE, Vol. 13, No. 12, 2018. https://doi.org/10.1371/journal.pone.0208168

[17] C.M. Riley, B.K. Lin, T.G. Habetter, R.R. Schoen, "A method for sensor-less on-line vibration monitoring of induction machines”,IEEE Trans. Ind. Appl., Vol. 34(6), pp. 1240-1245, 1998.

[18] G. Hancke, C. Viljoen, "The Microprocessor Measurement of Low Values of Rotational Speed and Acceleration ”, IEEE Transactions on Instrumentation and Measurement, Vol. 39, No. 6, pp. 1014-1017, 1990. 